\title{
Dutch institute forced to respond to crisis in recruitment of postdoctoral researchers
}

\section{Hoeven, Netherlands}

The Netherlands is faced with a crisis in the recruitment of postdoctoral researchers, with scientists increasingly reluctant to accept living on a series of short-term posts.

Figures from the medical council of the country's largest public research agency, the Netherlands Organization for Scientific Research (NWO), show that last year it filled less than a fifth of postdoctoral positions within its programme grants (see Table), only a third in its research support grants and just two thirds of its personal fellowships. Edvard Beem, deputy director of health research at the NWO, says that as a result it has been impossible for the council to request additional research funds from the NWO.

Problems in recruitment have also surfaced over the past two years at the Netherlands Cancer Institute (NKI) - a leading national research institute. Staff there say it is difficult to retain and attract postdocs to a country that does not have a large critical mass of research work.

Although there is no shortage of postdoctoral fellowships, the number of tenured positions in academia is limiting. Senior postdocs in particular feel unable to continue their scientific careers in the Netherlands

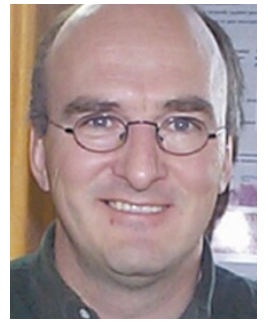

as short-term fellowships are unattractive to postdocs looking for career advancement and tenure. NKI staff and postdocs have dubbed this situation the 'postdoc paradox'.

"While universi-

Peters: postdocs want ties and institutes are permanent positions. looking for graduate students and postdocs, there is, at the same time, a population of ageing postdocs looking for a permanent position and recycling through standard postdoc positions," says Peter Peters, a researcher at NKI.

Unsurprisingly, 90 per cent of the postdocs are ultimately looking to find permanent university or research positions. "Postdocs that don't make it have limited alternative prospects in the Netherlands because of limited career possibilities in biotechnology and pharmaceutical industries in the country, and the general decay in existing research jobs in industry," explains Peters.

Recruitment difficulties are due to a variety of factors, he continues, most importantly a lack of career development and prospects. Some universities have had to readvertise postdoc jobs with better salaries and contract terms in order to recruit.

NKI's new director - Anton Berns last week responded to postdoc concerns, by establishing a novel junior faculty position that would give postdocs some degree of independence and career prospects. Junior faculty could apply for project grants with a senior staff member, would supervise graduate students, serve as senior authors on papers, carry projects with them when relocating to another laboratory and would also have their salaries boosted by about $\$ 5,000$.

Such a change is timely within a national, political context. A government report on science funding, published last year, stated that "the research establishment must itself take responsibility for developing a challenging personnel policy". In response, NWO will make available $\$ 0.7$ million per annum to improve the prospects for women in research and the science ministry will contribute a further $\$ 0.25$ million. Natasha Loder

Influx of personnel onto medical council grants Type of grant Granted (Jan 99) $\quad$ Filled (Dec 99) \% Fellowship support $\quad 12$ Research support $\quad 40$ Research programme 71

$\begin{array}{rr}8 & 66 \\ 12 & 30 \\ 13 & 18\end{array}$

\section{Appointment of UK food standards chief under fire}

\section{London}

Zoologist John Krebs, a former chief executive of the UK Natural Environment Research Council, has been appointed head of the country's Food Standards Agency (FSA), created in the wake of the crisis over bovine spongiform encephalopathy (BSE).

His nomination has been criticized by the powerful UK Consumers' Association, which expressed its "disappointment" that the government had not appointed a "strong, credible consumer chair". It argued that this would have been more in line with the food agency's goal of providing impartial assessments based on the best available scientific advice.

But former colleagues of Krebs are unanimous in their opinion that his diplomacy, fairness and ability to take tough decisions make him a good choice to head the FSA. One observer says, "he is not beholden to either side".

Krebs says his top priorities in the coming weeks will be to meet the representatives of consumer groups and industry to understand "more about what the issues in food safety and standards are". Krebs describes his job as being "at the interface between science and policy - a tremendously important and exciting area. Decisions [of the FSA] will have a firm basis in science, but science is not the total story".

Mistrust of public experts is rife since the BSE crisis (see Nature 400, 389; 1999). Krebs says the agency will try to rebuild trust by publishing the advice it gives. "If we make a recommendation on a particular issue and explain publicly why we've come to the conclusion and made the recommendation, and if ministers then choose to go a different way, then the public would quite rightly ask why," he says.

Krebs has a reputation for taking accurate but unpopular decisions. He was responsible for Krebs: trying to

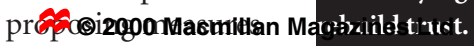
for tackling the issue of whether badgers with tuberculosis pass the disease to cattle. The experiment, which included the culling of around 12,500 badgers over five years, faced strong opposition from conservation and animalwelfare groups (see Nature 394, 821; 1998).

Until last September, Krebs was the chief executive of the Natural Environment Research Council. In 1988 he was appointed Royal Society research professor in the department of zoology at the University of Oxford.

In the light of the decision to appoint Krebs, the Consumers' Association is calling for the remaining FSA board members to have a stronger consumer focus. The association says it wants an end to the conflict of interest at the Ministry of Food, Fisheries and Agriculture between protecting consumers and promoting the food industry.

Krebs is certainly expected to do well in terms of the relationship between the FSA and the food ministry. He is also on close terms with the government's chief scientific adviser, Robert May. 